\title{
An anti-ferromagnetic terephthalate-bridged trigonal prismatic dinuclear manganese(II) complex: Synthon of rare anion $\cdots \pi$ interaction promoting dimensionality
}

\author{
SOMNATH CHOUBEY ${ }^{\mathrm{a}}$, SOUMI CHATTOPADHAYAY ${ }^{\mathrm{a}}$, KISHALAY BHAR ${ }^{\mathrm{a}}$, \\ SUBHASIS ROY ${ }^{\mathrm{a}}$, SUMITAVA KHAN ${ }^{\mathrm{a}}$, JOAN RIBAS ${ }^{\mathrm{b}}$ and BARINDRA KUMAR GHOSH ${ }^{\mathrm{a}, *}$ \\ ${ }^{a}$ Department of Chemistry, The University of Burdwan, Burdwan 713104, India \\ ${ }^{b}$ Departament de Quimica Inorganica, Universitat de Barcelona, Diagonal 647, 08028 Barcelona, Spain \\ e-mail: barin_1@yahoo.co.uk
}

MS received 26 December 2013; accepted 31 October 2014

\begin{abstract}
A dinuclear compound $\left[\mathrm{Mn}_{2}(\mathrm{~L})_{2}(\mu\right.$-tp) $]\left(\mathrm{PF}_{6}\right)_{2} \cdot 3.57 \mathrm{H}_{2} \mathrm{O}(\mathbf{1})\left[\mathrm{L}=\mathrm{N}, \mathrm{N}^{\prime}\right.$-(bis(pyridin-2-yl)benzylidene)-1,3-propanediamine and tp = terephthalate dianion] has been isolated and characterized on the basis of microanalytical, spectroscopic and other physicochemical properties. X-ray structural study showed interesting bis(bidentate) bridging motif of tp in the dicationic dinuclear unit $\left[\mathrm{Mn}_{2}(\mu \text {-tp) }]^{2+}\right.$. Each manganese(II) centre adopts a rare distorted trigonal prismatic geometry with an $\mathrm{MnN}_{4} \mathrm{O}_{2}$ chromophore. Chelation of the tetradentate Schiff base (L) along with bis(bidentate) bridging of two $\mathrm{O}$ atoms of tp complete hexacoordination around each manganese(II) centre. The dinuclear units of $\mathbf{1}$ are associated through cooperative $\mathrm{C}-\mathrm{H} \cdots \mathrm{F}$ hydrogen bonds and $\pi \cdots \pi, \mathrm{C}-\mathrm{H} \cdots \pi$ and rare anion $\cdots \pi$ interactions to promote the dimensionality in a graded manner. Variable temperature magnetic susceptibility measurement of $\mathbf{1}$ in the $2-300 \mathrm{~K}$ temperature range revealed weak antiferromagnetic interaction presumably due to long bridging arm of tp.
\end{abstract}

Keywords. Dinuclear manganese(II); N-donor schiff base; bis(bidentate) terephthalate bridge; anion $\cdots \pi$ interaction; magnetic behaviour

\section{Introduction}

The construction of diverse crystalline architectures ${ }^{1,2}$ is of current interest. In this regard non-covalent forces like hydrogen bonds, and $\pi \cdots \pi$ and $\mathrm{C}-\mathrm{H} \cdots \pi$ interaction $^{3-5}$ are of great mention. Recently, anion $\cdots \pi$ interaction, ${ }^{6-8,37}$ has gained special recognition as a fundamental weak force with significant implications in chemical and biological processes. These different secondary interactions have great significance in systematic design of veritable metal-organic frameworks (MOFs) coupled with various functionalities. ${ }^{9-14}$ Carboxylates like terephthalate (tp) have now been extensively used to prepare a great diversity of molecular and crystalline architecture ${ }^{15-17}$ due to their versatile ligational behaviour (scheme 1) leading to interesting topologies and magnetic behaviour ${ }^{9,10,18}$ with paramagnetic $3 \mathrm{~d}$ ions. Self-assembly ${ }^{19}$ using appropriate molar ratios of metal ions, organic ligands and tp is an efficient

*For correspondence approach to afford different MOFs ${ }^{15-17,20,21}$ with tunable properties. Schiff bases ${ }^{22}$ are useful organic ligands because of their ease of preparation, structural varieties and varied denticities. Currently, we are active $e^{23,24}$ in the isolation of different transition and post-transition metal complexes containing aliphatic/aromatic carboxylate bridges and $\mathrm{N}$-donor spacers to understand the effects of the variation in molar ratios of metal ions, blocking ligands, bridging units and counter ions, that may lead to varied molecular and crystalline architectures and properties. Recently, we reported ${ }^{23 a}$ the synthesis, structure and properties of a dinuclear manganese(II) carboxylate complex of the type $\left[\mathrm{Mn}_{2}(\mathrm{~L})_{2}(\mu\right.$-tp) $]\left(\mathrm{ClO}_{4}\right)_{2} \cdot \mathrm{H}_{2} \mathrm{O}\left[\mathrm{L}=\mathrm{N}, \mathrm{N}^{\prime}\right.$-(bis(pyridine2-yl)-benzylidene)-1,3-propanediamine] (scheme 2). To establish the effect of counter anions on nucleation, crystal packing and magnetic behaviour, herein we report a new manganese(II)-tp compound of the composition $\left[\mathrm{Mn}_{2}(\mathrm{~L})_{2}(\mu\right.$-tp) $]\left(\mathrm{PF}_{6}\right)_{2} \cdot 3.57 \mathrm{H}_{2} \mathrm{O}$ (1). The details of isolation, characterization, molecular and crystalline architectures, and thermal and magnetic properties of 1 with a different counter anion and varied crystallized solvent molecule are described. 
<smiles>COC(=O)c1ccc(C(=O)OC)cc1</smiles><smiles>c1cc(C2ONO2)ccc1C1NO1</smiles><smiles>O=C(O[Al])c1ccc(C2NO2)cc1</smiles><smiles>OC(OI)c1ccc(C2NO2)cc1</smiles><smiles>O=C(O[Al])c1ccc(C(O[Al])O[Al])cc1</smiles><smiles>COC(OC)c1ccc(C(OC)OI)cc1</smiles>

Scheme 1. Possible coordination modes of terephthalate (tp).

\section{Experimental}

\subsection{Materials}

High purity 1,3-propanediamine (Spectrochem, India), 2-benzoylpyridine (Lancaster, UK), terephthalic acid (Loba Chemie, India), piperidine (Loba Chemie, India), manganese(II) chloride (E. Merck, India) and ammonium hexaflurophosphate (Fluka, Germany) were purchased from respective concerns and were used as received. The Schiff base, N,N'-(bis-(pyridin2-yl)benzylidene)-1,3-propanediamine (L) was prepared by condensation of 1:2 molar ratio of 1,3propanediamine and 2-benzoylpyridine using the reported method. ${ }^{23 a}$ Piperidinium terephthalte (ptp) was isolated by following a method described elsewhere. ${ }^{25}$ All other chemicals and solvents used were AR grade.

\subsection{Physical measurements}

Elemental analysis was performed on a Perkin-Elmer $2400 \mathrm{CHNS} / \mathrm{O}$ elemental analyzer. Molar conductance was measured using a Systronics conductivity meter where the cell constant was calibrated with $0.01 \mathrm{M} \mathrm{KCl}$ solution and dry DMF was used as solvent. IR spectrum (KBr discs, 4000-400 $\mathrm{cm}^{-1}$ ) was recorded using a Perkin-Elmer FTIR model RX1 spectrometer. Thermal

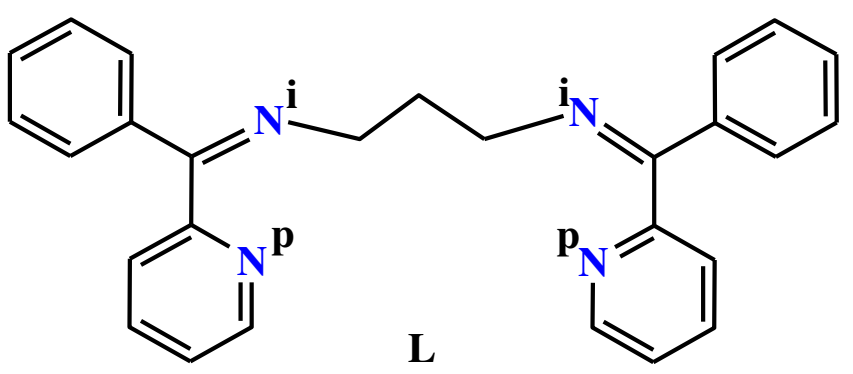

Scheme 2. $\left(\mathrm{N}^{\mathrm{p}}, \mathrm{N}^{\mathrm{i}}, \mathrm{N}^{\mathrm{i}}, \mathrm{N}^{\mathrm{p}}\right)$ donor set in $\mathrm{L}$. behaviour was examined with a Perkin-Elmer Diamond TG/DT analyzer heated from $35-740^{\circ} \mathrm{C}$ under nitrogen. Ground state absorption (in dry DMF) was made with a Shimadzu model UV-2450 UV-Vis spectrophotometer. The temperature-dependence magnetic susceptibility was measured on polycrystalline sample with a Quantum Design SQUID MPMS-XL susceptometer operating at a magnetic field $0.1 \mathrm{~T}$ over a temperature range 2-300 K. The diamagnetic correction was evaluated from Pascal's constants.

\subsection{Isolation of the complex $\left[\mathrm{Mn}_{2}(L)_{2}(\mu-t p)\right]\left(P F_{6}\right)_{2}$. $3.57 \mathrm{H}_{2} \mathrm{O}(1)$}

Compound 1 was isolated following the similar procedure $^{22 \mathrm{a}}$ as reported earlier but with a little modification. $\mathrm{L}(0.096 \mathrm{~g}, 0.24 \mathrm{mmol})$ in methanol $(10 \mathrm{~mL})$ was added dropwise to a light pink solution of $\mathrm{MnCl}_{2} \cdot 4 \mathrm{H}_{2} \mathrm{O}$ $(0.048 \mathrm{~g}, 0.24 \mathrm{mmol})$ dissolved in the same solvent $(10$ $\mathrm{mL})$. Ptp $(0.040 \mathrm{~g}, 0.12 \mathrm{mmol})$ followed by $\mathrm{NH}_{4} \mathrm{PF}_{6}$ $(0.0446 \mathrm{~g}, 0.2 \mathrm{mmol})$, each taken in methanol $(5 \mathrm{~mL})$, were added to the mixture. The final yellowish brown solution was left undisturbed in an open air for slow evaporation. After a week, yellow microcrystals of $\mathbf{1}$ that were deposited, were collected by filtration and dried in vacuo over silica gel indicator. Yield: 0.1154 g (75\%). Anal. Calc. for $\mathrm{C}_{62} \mathrm{H}_{52} \mathrm{~N}_{8} \mathrm{O}_{7.57} \mathrm{~F}_{12} \mathrm{P}_{2} \mathrm{Mn}_{2}(\mathbf{1})$ : C, 52.07; H, 3.67; N, 7.84\% Found: C, 52.14; H, 3.53; N, $8.01 \%$. IR $\left(\mathrm{KBr}, \mathrm{cm}^{-1}\right): v_{\text {as }}\left(\mathrm{COO}^{-}\right) 1560 ; v_{\mathrm{s}}\left(\mathrm{COO}^{-}\right)$ $1389 ; v(\mathrm{C}=\mathrm{N})+v(\mathrm{C}=\mathrm{C}) 1623,1595 ; v\left(\mathrm{PF}_{6}^{-}\right) 843,558$. $\Lambda_{\mathrm{M}}\left(\mathrm{DMF}, \mathrm{ohm}^{-1} \mathrm{~cm}^{2} \mathrm{~mol}^{-1}\right): 238$. UV-Vis $(\lambda, \mathrm{nm})$ : 277.

\section{$2.4 X$-ray crystallographic analysis}

Single crystal of $\mathbf{1}$ suitable for X-ray analysis was selected from those obtained by slow evaporation of methanolic solution of the reaction mixture at room temperature. Diffraction data was collected at 100(2) $\mathrm{K}$ on a Bruker APEX CCD area-detector diffractometer using graphite monochromated Mo-K $\alpha$ radiation $(\lambda=0.71073 \AA)$. Intensity data were reduced using SAINT $^{26}$ and the empirical absorption corrections were performed with $\mathrm{SADABS}^{27}$ program. The structure was solved by SHELXS-97 ${ }^{28}$ and refined by full-matrix least-squares methods based on $|F|^{2}$ using the program SHELXL-97. ${ }^{28}$ All non-hydrogen atoms were refined anisotropically. Hydrogen atoms were placed in calculated positions and constrained to ride on their parent atoms. One benzene ring $(\mathrm{C} 17 \mathrm{~A}, \mathrm{C} 18 \mathrm{~A}$, C19A,C20A,C21A,C22A/C17C,C18C,C19C,C20C, C21C,C22C atoms with $57 / 43 \%$ occupancy) and the 
propylenic arm of $\mathrm{L}(\mathrm{C} 13 \mathrm{~A}, 14 \mathrm{~A}, 15 \mathrm{~A} / \mathrm{C} 13 \mathrm{C}, 14 \mathrm{C}, 15 \mathrm{C}$ atoms with $57 / 43 \%$ occupancy) and $\mathrm{O}$ atoms of water molecules $(\mathrm{O} 2 \mathrm{C}, \mathrm{O} 3 \mathrm{C}, \mathrm{O} 6 \mathrm{C} / \mathrm{O} 4 \mathrm{C}, \mathrm{O} 5 \mathrm{C}$ with $57 / 43 \%)$ are in positional disordered state. All the calculations were carried out using PLATON, ${ }^{29}$ Diamond, ${ }^{30}$ X-Seed ${ }^{31}$ and Mercury $3.1^{32}$ programs. The crystallographic data for the complex 1 are summarized in table 1.

\section{Results and Discussions}

\subsection{Synthesis and formulation}

Use of a 2:2:1:2 molar ratio of manganese(II) chloride tetrahydrate, tetradentate Schiff base $(\mathrm{L})$, piperidinium terephthalate (ptp) and $\mathrm{NH}_{4} \mathrm{PF}_{6}$ in methanol at room temperature afforded Eq. (1) hexacoordinated dicationic dinuclear compund $\left[\mathrm{Mn}_{2}(\mathrm{~L})_{2}(\mu\right.$-tp) $]\left(\mathrm{PF}_{6}\right)_{2} \cdot 3.57$ $\mathrm{H}_{2} \mathrm{O}(\mathbf{1})$ in good

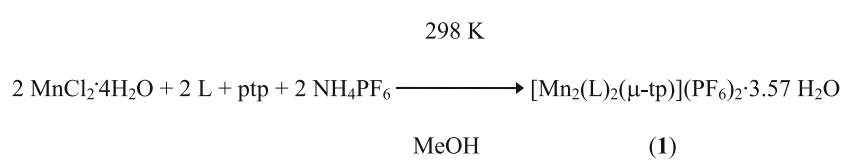

yield. The compound was characterized using microanalysis, spectroscopic and thermal study. The microanalytical results are in good agreement with formulation of $\mathbf{1}$. The air-stable compound is soluble in a wide range of common organic solvents such as MeCN, DMF and DMSO but is insoluble in water. In DMF solution, a 1:1 electrolytic nature ${ }^{33}$ was observed for $\mathbf{1}\left(\Lambda_{\mathrm{M}}: 238\right.$ $\left.\mathrm{ohm}^{-1} \mathrm{~cm}^{2} \mathrm{~mol}^{-1}\right)$.

\subsection{Spectroscopic studies}

In IR spectrum, $v(\mathrm{C}=\mathrm{N})$ plus $v(\mathrm{C}=\mathrm{C})$ stretching vibrations of the metal-bound Schiff base are observed at 1623 and $1595 \mathrm{~cm}^{-1}$. The stretching vibrations of tp are seen as strong $v_{\text {as }}\left(\mathrm{COO}^{-}\right)$stretch at $1560 \mathrm{~cm}^{-1}$ and $v_{\mathrm{s}}\left(\mathrm{COO}^{-}\right)$band at $1389 \mathrm{~cm}^{-1}$. The value for the difference between $v_{\mathrm{as}}\left(\mathrm{COO}^{-}\right)$and $v_{\mathrm{s}}\left(\mathrm{COO}^{-}\right)$stretching frequencies $(\Delta)$ in the IR spectrum of the compound reflects bis(bidentate) bridging $(\mathbf{1}: \Delta=171$, ptp: $\Delta=163$ ) motif of tp. ${ }^{34}$ Additionally, presence of hexaflurophosphate stretches at 843 and $558 \mathrm{~cm}^{-1}$ (vide Experimental) are noticed indicating counter anionic view $^{34 b}$ with no metal coordination. X-ray study corroborates this hypothesis. Yellow DMF solution of $\mathbf{1}$ exhibits band at $\lambda_{\max }$ value $277 \mathrm{~nm}$ assignable to ligandbased charge transfer transition ${ }^{35}$ since the free ligand, $\mathrm{L}$ also shows a strong band at $271 \mathrm{~nm}$.
Table 1. Crystallographic data and structure refinement in 1.

\begin{tabular}{|c|c|}
\hline Compound & 1 \\
\hline Formula & $\mathrm{C}_{62} \mathrm{H}_{52} \mathrm{~N}_{8} \mathrm{O}_{7.57} \mathrm{~F}_{12} \mathrm{P}_{2} \mathrm{Mn}_{2}$ \\
\hline Formula weight & 1430.06 \\
\hline Crystal size $\left(\mathrm{mm}^{3}\right)$ & $0.25 \times 0.25 \times 0.13$ \\
\hline Crystal system & Monoclinic \\
\hline Space group & $\mathrm{Cc}$ \\
\hline$a(\AA)$ & $14.3910(17)$ \\
\hline$b(\AA)$ & $19.505(2)$ \\
\hline$c(\AA)$ & $23.966(3)$ \\
\hline$\alpha\left(^{\circ}\right)$ & 90.00 \\
\hline$\beta\left(^{\circ}\right)$ & $101.415(2)$ \\
\hline$\gamma\left({ }^{\circ}\right)$ & 90.00 \\
\hline$V\left(\AA^{3}\right)$ & $6594.3(13)$ \\
\hline$\lambda(\AA)$ & 0.71073 \\
\hline$\rho_{\text {calcd }}\left(\mathrm{g} \mathrm{cm}^{-3}\right)$ & 1.440 \\
\hline$Z$ & 4 \\
\hline $\mathrm{T}(\mathrm{K})$ & $100(2)$ \\
\hline$\mu\left(\mathrm{mm}^{-1}\right)$ & 0.523 \\
\hline$F(000)$ & 2914 \\
\hline$\theta$ ranges $\left(^{\circ}\right)$ & 1.73 to 28.01 \\
\hline$h / k / l$ & $-18,18 /-25,21 /-31,30$ \\
\hline Reflections collected & 19739 \\
\hline Independent reflections & 11585 \\
\hline Data/restraints/parameters & $11585 / 14 / 815$ \\
\hline Goodness-of-fit on $F^{2}$ & 1.025 \\
\hline $\mathrm{T}_{\max }$ and $\mathrm{T}_{\min }$ & 0.9375 and 0.8803 \\
\hline$R_{i n t}$ & 0.027 \\
\hline Final $R$ indices $[I>2 \sigma(I)]$ & $R=0.0624, w R=0.1664$ \\
\hline$R$ indices (all data) & $R=0.0740, w R=0.1785$ \\
\hline Largest peak and hole $\left(\mathrm{e} \AA^{-3}\right)$ & 1.168 and -0.707 \\
\hline
\end{tabular}

\subsection{Molecular and crystalline structures of $\left[\mathrm{Mn}_{2}(\mathrm{~L})_{2}(t p)\right]\left(\mathrm{PF}_{6}\right)_{2} \cdot 3.57 \mathrm{H}_{2} \mathrm{O}(\mathbf{1})$}

Structural analysis reveals that compound $\mathbf{1}$ is made up of terephthalate (tp) bridged disordered dicationic dinuclear unit $\left[\mathrm{Mn}_{2}(\mathrm{~L})_{2}(\mathrm{tp})\right]^{2+}$ with a tetradentate Schiff base (L) as end-capping ligand, noncoordinated hexafluorophosphate counter anions and 3.57 units crystalline water molecules without hydrogen atoms. On the other hand, the perchlorate analogue $\left[\mathrm{Mn}_{2}(\mathrm{~L})_{2}(\mathrm{tp})\right]\left(\mathrm{ClO}_{4}\right)_{2} \cdot \mathrm{H}_{2} \mathrm{O}^{23 \mathrm{a}}$ of $\mathbf{1}$ with centrosymmetric environment has only one non-coordinated water molecule with hydrogen atoms. Perspective view of the dinuclear entity in $\mathbf{1}$ is shown in figure 1 . Selected bond distances and angles are given in table 2 . In the dication, the manganese(II) centres are bound by chelation of $\mathrm{L}$ and bis(bidentate) bridging motifs of tp with an M. . . M separation of $10.925 \AA$. 


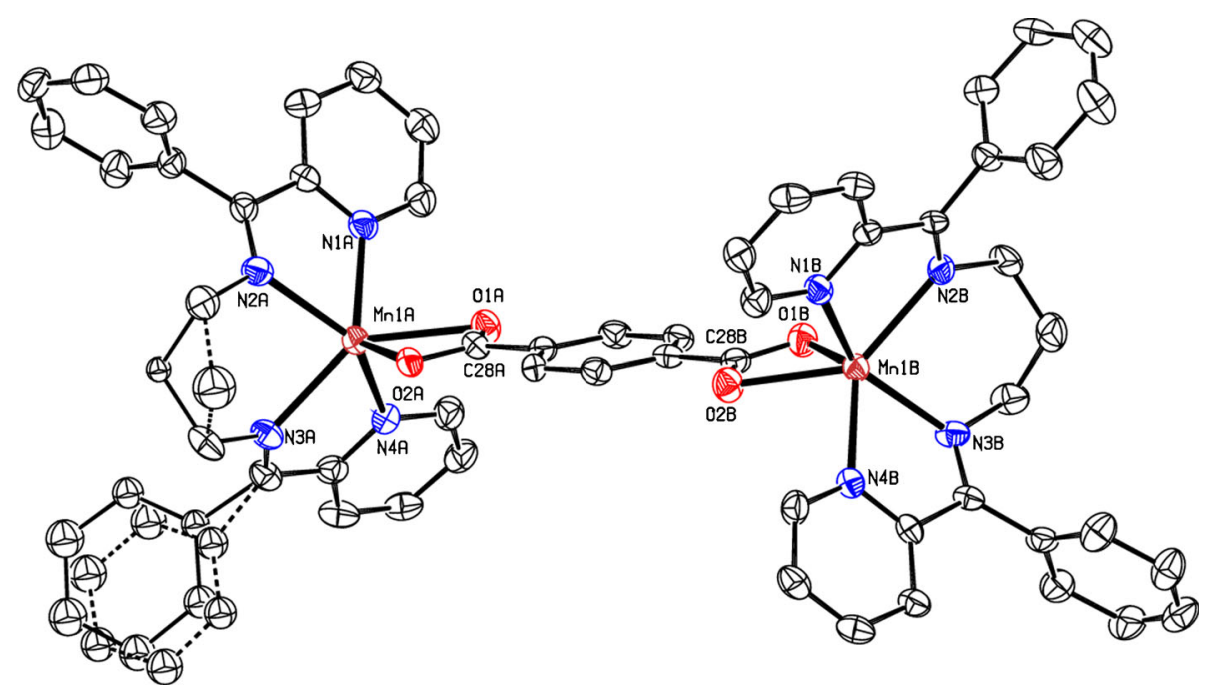

Figure 1. Molecular structure of $\left[\mathrm{Mn}_{2}(\mathrm{~L})_{2}(\mu-\mathrm{tp})\right]^{2+}$ in 1 with atom numbering schemes (50\% probability ellipsoid for all non-hydrogen atoms).

Each manganese(II) centre adopts a rare distorted trigonal prismatic geometry ${ }^{36}$ with an $\mathrm{MnN}_{4} \mathrm{O}_{2}$ chromophore. Each of the two trigonal faces of the prism (figure 2) is occupied by two $\mathrm{N}$ atoms of the Schiff base $\mathrm{L}$ and one $\mathrm{O}$ atom of bis(bidenate) tp bridging unit $(\mathrm{O} 2 \mathrm{~A}, \mathrm{~N} 2 \mathrm{~A}, \mathrm{~N} 3 \mathrm{~A}$ and $\mathrm{O} 1 \mathrm{~A}, \mathrm{~N} 1 \mathrm{~A}, \mathrm{~N} 4 \mathrm{~A}$ for $\mathrm{Mn} 1 \mathrm{~A}$ and $\mathrm{O} 1 \mathrm{~B}, \mathrm{~N} 2 \mathrm{~B}, \mathrm{~N} 3 \mathrm{~B}$ and $\mathrm{O} 2 \mathrm{~B}, \mathrm{~N} 1 \mathrm{~B}$, $\mathrm{N} 4 \mathrm{~B}$ for Mn1B). The trigonal faces are away by a small distance than that expected for an ideal trigonal prismatic geometry. ${ }^{36} \mathrm{~A}$ major reason for distortion from the trigonal prismatic geometry is the presence of two $\mathrm{O}$ atoms of tp $(\mathrm{O} 1 \mathrm{~A}, \mathrm{O} 2 \mathrm{~A} / \mathrm{O} 1 \mathrm{~B}, \mathrm{O} 2 \mathrm{~B}$ for $\mathrm{Mn} 1 \mathrm{~A} / \mathrm{Mn} 1 \mathrm{~B})$ on the two opposite faces creating small bite angle [58.69(13)/58.66(14) ${ }^{\circ}$ for $\left.\mathrm{Mn} 1 \mathrm{~A} / \mathrm{Mn} 1 \mathrm{~B}\right]$. The mean planes of these two faces containing O2A, N2A,
$\mathrm{N} 3 \mathrm{~A}$ and O1A, N1A, N4A atoms for Mn1A and O1B, $\mathrm{N} 2 \mathrm{~B}, \mathrm{~N} 3 \mathrm{~B}$ and $\mathrm{O} 2 \mathrm{~B}, \mathrm{~N} 1 \mathrm{~B}, \mathrm{~N} 4 \mathrm{~B}$ atoms for Mn1B are slightly twisted from the ideal value of $0^{\circ}$ creating angles of $7.97^{\circ}$ (for $\mathrm{Mn} 1 \mathrm{~A}$ ) and $8.54^{\circ}$ (for $\mathrm{Mn} 1 \mathrm{~B}$ ) with each other. The carboxylate group shows the expected trigonal geometry ${ }^{15 a}$ with intracarboxylate bond angle O1A-C28A-O2A/O1B-C28B-O2B: $121.4(5) / 120.2(5)^{\circ}$ for Mn1A/Mn1B (table 2). However, significant differences are observed in the values of the carbonoxygen bond distance the value is $1.254(7) / 1.271(6)$ $\AA$ (Mn1A), 1.296(6)/1.236(7) $\AA$ (Mn1B) for the symmetrical chelating carboxylato coordination. The Mn-N bond lengths are in the range 2.227(5)-2.254(4) $\AA$ for Mn1A and 2.207(5)-2.269(4) $\AA$ for Mn1B (table 2) and Mn-O distances are in the range 2.182(4)-2.306(4) $\AA$

Table 2. Selected bond distances $(\AA)$ and bond angles $\left({ }^{\circ}\right)$ for $\mathbf{1}$.

\begin{tabular}{|c|c|c|c|c|c|}
\hline \multirow{2}{*}{$\frac{\text { Bond distances for } \mathbf{1}}{\text { Mn1A-N1A }}$} & \multicolumn{5}{|c|}{ Bond angles for $\mathbf{1}$} \\
\hline & $2.230(4)$ & N1A-Mn1A-N2A & $73.21(16)$ & N1B-Mn1B-N2B & $73.05(16)$ \\
\hline Mn1A-N2A & $2.244(5)$ & N1A-Mn1A-N3A & 133.31(16) & N1B-Mn1B-N3B & $144.99(17)$ \\
\hline Mn1A-N3A & $2.254(4)$ & N1A-Mn1A-N4A & 102.67(17) & N1B-Mn1B-N4B & $103.11(16)$ \\
\hline Mn1A-N4A & $2.227(5)$ & N2A-Mn1A-N3A & $82.93(17)$ & N2B-Mn1B-N3B & $84.69(16)$ \\
\hline Mn1B-N1B & $2.221(5)$ & N2A-Mn1A-N4A & $141.37(16)$ & N2B-Mn1B-N4B & $134.08(16)$ \\
\hline Mn1B-N2B & $2.269(4)$ & N3A-Mn1A-N4A & $72.43(17)$ & N3B-Mn1B-N4B & $73.38(16)$ \\
\hline Mn1B-N3B & $2.207(5)$ & O1A-Mn1A-N1A & $84.42(15)$ & O1B-Mn1B-N1B & $112.86(16)$ \\
\hline Mn1B-N4B & $2.233(4)$ & O1A-Mn1A-N2A & 130.91(16) & O1B-Mn1B-N2B & $98.06(16)$ \\
\hline Mn1A-O1A & $2.306(4)$ & O1A-Mn1A-N3A & 138.95(16) & O1B-Mn1B-N3B & $96.48(16)$ \\
\hline Mn1A-O2A & $2.182(4)$ & O1A-Mn1A-N4A & $85.39(16)$ & O1B-Mn1B-N4B & $123.69(16)$ \\
\hline Mn1B-O1B & $2.196(4)$ & O2A-Mn1A-N1A & $120.58(15)$ & O2B-Mn1B-N1B & $84.55(15)$ \\
\hline Mn1B-O2B & $2.281(4)$ & O2A-Mn1A-N2A & $96.30(16)$ & $\mathrm{O} 2 \mathrm{~B}-\mathrm{Mn} 1 \mathrm{~B}-\mathrm{N} 2 \mathrm{~B}$ & $138.26(16)$ \\
\hline C28A-O1A & $1.254(7)$ & O2A-Mn1A-N3A & $101.15(15)$ & O2B-Mn1B-N3B & $128.56(17)$ \\
\hline C28A-O2A & $1.271(6)$ & O2A-Mn1A-N4A & $117.03(15)$ & O2B-Mn1B-N4B & $84.58(15)$ \\
\hline C28B-O1B & $1.296(6)$ & O1A-C28A-O2A & $121.4(5)$ & O1B-C28B-O2B & $120.2(5)$ \\
\hline C28B-O2B & $1.236(7)$ & O1A-Mn1A-O2A & $58.69(13)$ & O1B-Mn1B-O2B & $58.66(14)$ \\
\hline
\end{tabular}



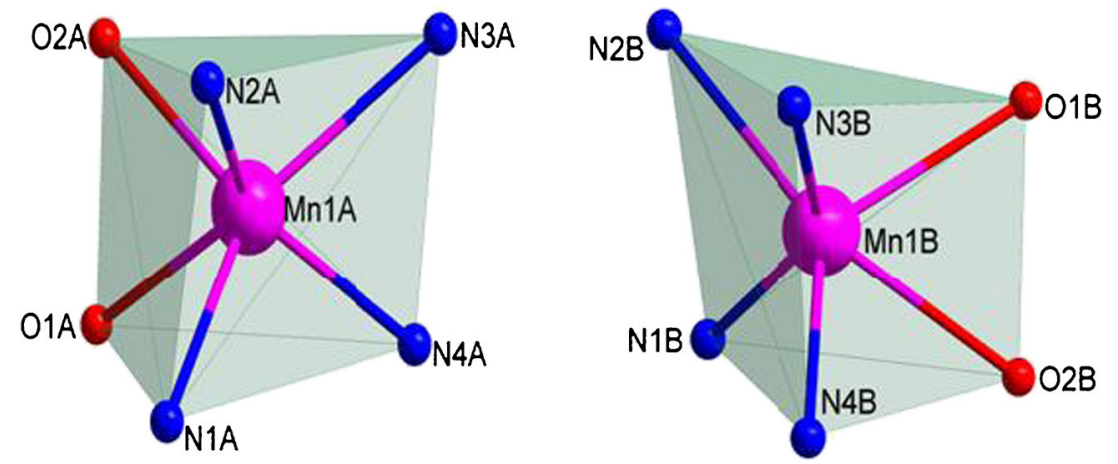

Figure 2. Trigonal prismatic coordination environment of Mn1A and Mn1B in $\mathbf{1}$.

(for Mn1A) and 2.196(4)-2.281(4) A. The Mn-N and $\mathrm{Mn}-\mathrm{O}$ bond distances are similar to those reported in literature. ${ }^{23 a}$ The tetradentate Schiff base $(\mathrm{L})$ is twisted around the manganese(II) centre such that the two planes containing the unsaturated chelate rings (Mn1, $\mathrm{N} 1, \mathrm{C} 5, \mathrm{C} 6, \mathrm{~N} 2)$ and $(\mathrm{Mn} 1, \mathrm{~N} 3, \mathrm{C} 16, \mathrm{C} 23, \mathrm{~N} 4)$ are inclined to each other at $60.63 / 56.52^{\circ}(\mathrm{Mn} 1 \mathrm{~A} / \mathrm{Mn} 1 \mathrm{~B})$ in 1. The propylenic arm of $\mathrm{L}$ in the saturated sixmembered chelate ring is to some extent puckered. The value of dihedral angle between O1A, C28A, O2A/O1B, C28B, O2B carboxylate group and benzene ring (C29A, 30A, C31A, C29B, C30B, C31B) of tp is $2.62^{\circ} / 7.15^{\circ}$ which is indicative of quasi-planarity of the bridging unit on coordination.

Table 3. $\pi \cdots \pi, \mathrm{C}-\mathrm{H}^{\cdots} \pi$, anion $\cdots \pi$ interactions and hydrogen bond parameters $\left(\AA,^{\circ}\right)$ for $\mathbf{1}$.

\begin{tabular}{|c|c|c|c|c|c|}
\hline \multicolumn{6}{|c|}{$\pi^{\cdots} \pi$ interactions $\left(\AA,{ }^{\circ}\right)$} \\
\hline $\mathrm{Cg}-\mathrm{Cg}$ & $\mathrm{Cg}-\mathrm{Cg}$ distance & Dihedral angle $(i, j)$ & \multicolumn{2}{|c|}{$\begin{array}{l}\text { Perpendicular distances } \\
\text { between baricentres }(i, j)\end{array}$} & Symmetry code \\
\hline $\operatorname{Cg} 10 \cdots \operatorname{Cg} 13$ & $4.377(3)$ & $2.1(3)$ & \multicolumn{2}{|c|}{$4.105(2)$ and $4.061(2)$} & $1 / 2+\mathrm{x}, 1 / 2+\mathrm{y}, \mathrm{z}$ \\
\hline $\mathrm{Cg} 13 \cdots \mathrm{Cg} 10$ & $4.377(3)$ & $2.1(3)$ & \multicolumn{2}{|c|}{ 4.061(2) and 4.105(2) } & $-1 / 2+\mathrm{x},-1 / 2+\mathrm{y}, \mathrm{z}$ \\
\hline $\mathrm{Cg} 11 \cdots \mathrm{Cg} 12$ & $3.978(3)$ & $6.0(3)$ & \multicolumn{2}{|c|}{$3.829(2)$ and 3.902(2) } & $1 / 2+\mathrm{x},-1 / 2+\mathrm{y}, \mathrm{z}$ \\
\hline $\mathrm{Cg} 12 \cdots \mathrm{Cg} 11$ & $3.978(3)$ & $6.0(3)$ & \multicolumn{2}{|c|}{$3.902(2)$ and 3.829(2) } & $-1 / 2+\mathrm{x}, 1 / 2+\mathrm{y}, \mathrm{z}$ \\
\hline \multicolumn{6}{|c|}{$\mathrm{C}-\mathrm{H} \pi$ interactions $\left(\AA,^{\circ}\right)$} \\
\hline $\mathrm{D}-\mathrm{H} \cdots \mathrm{A}$ & D-H & $\mathrm{H} \cdots \mathrm{A}$ & $\mathrm{D} \cdots \mathrm{A}$ & $\mathrm{D}-\mathrm{H} \cdots \mathrm{A}$ & Symmetry code \\
\hline C14B-H14F. . Cg16 & 0.989 & 2.70 & $3.651(7)$ & 160 & $\mathrm{x},-\mathrm{y},-1 / 2+\mathrm{z}$ \\
\hline C14B-H14F. . Cg19 & 0.989 & 2.77 & $3.710(8)$ & 158 & $\mathrm{x},-\mathrm{y},-1 / 2+\mathrm{z}$ \\
\hline \multicolumn{6}{|c|}{ Anion $\cdots \pi$ interactions $\left(\AA,^{\circ}\right)$} \\
\hline$X-D \cdots A$ & $\mathrm{X}-\mathrm{D}$ & $\mathrm{D} \cdots \mathrm{A}$ & $\mathrm{X} \cdots \mathrm{A}$ & $\mathrm{X}-\mathrm{D} \cdots \mathrm{A}$ & Symmetry code \\
\hline P1A-F1A …Cg13 & $1.584(4)$ & $3.107(5)$ & $4.227(3)$ & $125.4(2)$ & $\mathrm{x}, 1+\mathrm{y}, \mathrm{z}$ \\
\hline P1A-F2A …Cg11 & $1.591(4)$ & $3.198(5)$ & $4.314(3)$ & $125.1(2)$ & $\mathrm{x}, 1+\mathrm{y}, \mathrm{z}$ \\
\hline P1A-F3A … Cg10 & $1.593(4)$ & $3.134(5)$ & $4.213(3)$ & $122.7(2)$ & $\mathrm{x}, \mathrm{y}, \mathrm{z}$ \\
\hline P1A-F3A $\cdots \mathrm{Cg} 11$ & $1.593(4)$ & $3.842(5)$ & $4.314(3)$ & $96.12(17)$ & $\mathrm{x}, 1+\mathrm{y}, \mathrm{z}$ \\
\hline P1A-F4A $\cdots \mathrm{Cg} 12$ & $1.603(4)$ & $3.173(5)$ & $4.216(3)$ & $120.3(2)$ & $\mathrm{x}, \mathrm{y}, \mathrm{z}$ \\
\hline \multicolumn{6}{|c|}{ Hydrogen bond parameters $\left(\AA,^{\circ}\right)$} \\
\hline $\mathrm{D}-\mathrm{H} \cdots \mathrm{A}$ & D-H & $\mathrm{H} \cdots \mathrm{A}$ & $\mathrm{D} \cdots \mathrm{A}$ & $\mathrm{D}-\mathrm{H} \cdots \mathrm{A}$ & Symmetry code \\
\hline C1B-H1B $\cdots$ F1B & 0.9500 & 2.5400 & $3.375(8)$ & 147.00 & $1 / 2+\mathrm{x},-1 / 2 s+\mathrm{y}, \mathrm{z}$ \\
\hline $\mathrm{C} 2 \mathrm{~A}-\mathrm{H} 2 \mathrm{~A} \cdots \mathrm{F} 3 \mathrm{~B}$ & 0.9500 & 2.4700 & $3.291(8)$ & 144.00 & $1 / 2+\mathrm{x}, 1 / 2-\mathrm{y},-1 / 2+\mathrm{z}$ \\
\hline $\mathrm{C} 2 \mathrm{~A}-\mathrm{H} 2 \mathrm{~A} \cdots \mathrm{F} 4 \mathrm{~B}$ & 0.9500 & 2.5400 & $3.428(8)$ & 155.00 & $1 / 2+\mathrm{x}, 1 / 2-\mathrm{y},-1 / 2+\mathrm{z}$ \\
\hline C26B-H26B $\cdots$ F6B & 0.9500 & 2.4400 & $3.173(9)$ & 134.00 & $1 / 2+\mathrm{x},-1 / 2+\mathrm{y}, \mathrm{z}$ \\
\hline C12B-H12B $\cdots$ F3A & 0.9500 & 2.5400 & $3.431(8)$ & 156.00 & $\mathrm{x},-1+\mathrm{y}, \mathrm{z}$ \\
\hline
\end{tabular}

$\mathrm{Cg}(10): \mathrm{N}(1 \mathrm{~A})-\mathrm{C}(1 \mathrm{~A})-\mathrm{C}(2 \mathrm{~A})-\mathrm{C}(3 \mathrm{~A})-\mathrm{C}(4 \mathrm{~A})-\mathrm{C}(5 \mathrm{~A})$;

$\mathrm{Cg}(11): \mathrm{N}(1 \mathrm{~B})-\mathrm{C}(1 \mathrm{~B})-\mathrm{C}(2 \mathrm{~B})-\mathrm{C}(3 \mathrm{~B})-\mathrm{C}(4 \mathrm{~B})-\mathrm{C}(5 \mathrm{~B})$;

$\mathrm{Cg}(12): \mathrm{N}(4 \mathrm{~A})-\mathrm{C}(23 \mathrm{~A})-\mathrm{C}(24 \mathrm{~A})-\mathrm{C}(25 \mathrm{~A})-\mathrm{C}(26 \mathrm{~A})-\mathrm{C}(27 \mathrm{~A})$;

$\mathrm{Cg}(13): \mathrm{N}(4 \mathrm{~B})-\mathrm{C}(23 \mathrm{~B})-\mathrm{C}(24 \mathrm{~B})-\mathrm{C}(25 \mathrm{~B})-\mathrm{C}(26 \mathrm{~B})-\mathrm{C}(27 \mathrm{~B})$;

$\mathrm{Cg}(16)$ : C(17A)-C(18A)-C(19A)-C(20A)-C(21A)-C(22A), and

$\mathrm{Cg}(19)$ : C(17C)-C(18C)-C(19C)-C(20C)-C(21C)-C(22C). 
In the crystalline state, individual dinuclear units of $\mathbf{1}$ are assembled through different types of $\mathrm{C}-\mathrm{H} \cdots \mathrm{F}$ hydrogen bonds with $\mathrm{R}_{1}^{2}(4)$ and $\mathrm{R}_{2}^{2}(11)$ cyclic motifs in Etter's graph notation ${ }^{37}$ along with $\mathrm{C}-\mathrm{H} \cdots \pi$ interactions (table 3 ) in a cooperative manner resulting in 1D chain structure parallel to crystallographic $c$-axis (figure 3a). The chains are further connected via anion $\cdots \pi$ interactions to form a flat $2 \mathrm{D}$-sheet structure parallel to $b c$-plane (figure $3 b$ ). The dinuclear units of 1 are also associated to each other via $\pi \cdots \pi$ interactions (table 3 ) between two closest pyridine rings (Cg10-Cg13 and $\mathrm{Cg} 11-\mathrm{Cg} 12$ ) of $\mathrm{L}$ affording a 2D sheet structure (figure 4a) parallel to $a b$-plane. Each 2D sheet is further stabilized by various types of anion $\cdots \pi$ interactions (table 3 and figure $4 \mathrm{~b}$ ) between F-atoms of the embedded hexafluorophosphate anions and pyridine rings ( $\mathrm{Cg} 10, \mathrm{Cg} 11, \mathrm{Cg} 12$ and $\mathrm{Cg} 13)$. To sum it up, such cooperative $\mathrm{C}-\mathrm{H} \cdots \mathrm{F}$ hydrogen bonds and $\pi \cdots \pi, \mathrm{C}$ $\mathrm{H}^{\cdots} \pi$ and anion $\cdots \pi$ interactions promote the dimensionality of the dinuclear 0D unit to a 3D network structure (figure 5).

Here it is worth mentioning that instead of distorted trigonal prismatic structure of each manganese(II) centre in this hexafluorophosphate salt $\mathbf{1}$, distorted octahedral geometry of each metal(II) centre is observed in the corresponding perchlorate analogue, $\left[\mathrm{Mn}_{2}(\mathrm{~L})_{2}(\mu\right.$ tp) $]\left(\mathrm{ClO}_{4}\right)_{2} \cdot \mathrm{H}_{2} \mathrm{O} \cdot{ }^{23 a}$ So, an interesting change in coordination geometry and thereby molecular architecture of the hexacoordinated manganese(II) is revealed just by variation of counter anion from tetrahedral perchlorate to octahedral hexafluorophosphate. Again, in the crystalline state, $\mathbf{1}$ shows a rare anion $\cdots \pi$ interaction which is absent in the perchlorate analogue. The other non-covalent forces present are $\mathrm{C}-\mathrm{H} . . \mathrm{O}$ and $\mathrm{O}-\mathrm{H} \cdots \mathrm{O}$

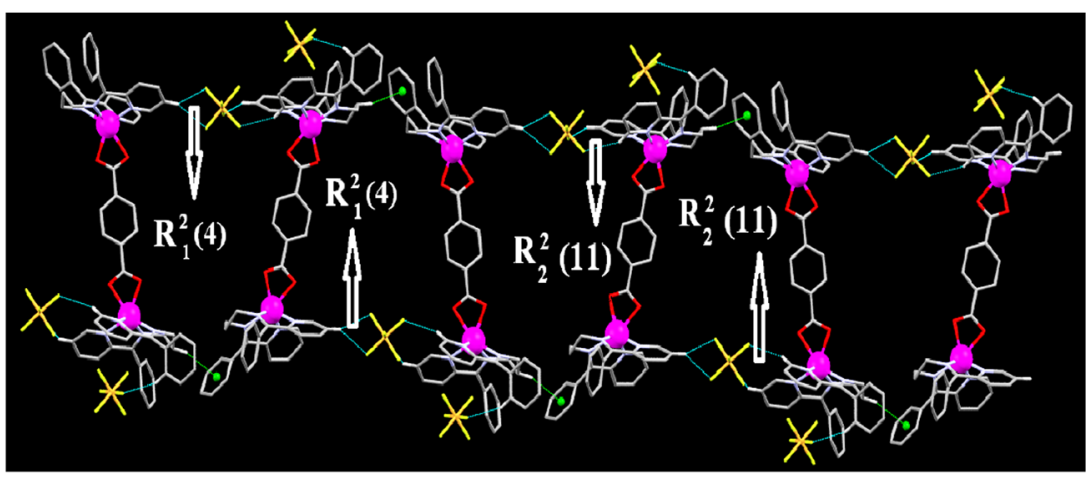

(a)

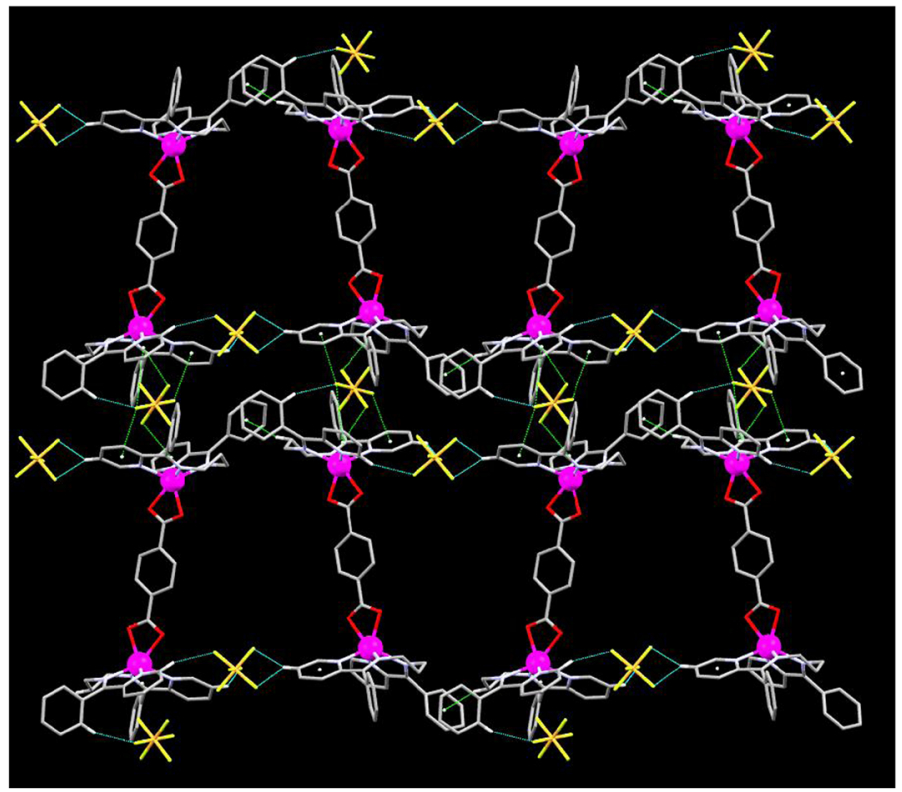

(b)

Figure 3. (a) $1 \mathrm{D}$ chain structure in $\mathbf{1}$ parallel to c-axis through cooperative $\mathrm{C}-\mathrm{H}^{\cdots} \pi$ interactions and $\mathrm{C}-\mathrm{H}^{\cdots} \cdots \mathrm{F}$ hydrogen bonds with $\mathrm{R}_{1}^{2}(4)$ and $\mathrm{R}_{2}^{2}(11)$ cyclic motifs in Etter's graph notation; (b) formation of 2D sheet structure parallel to bc-plane through various anion $\cdots \pi$ interactions of the $1 \mathrm{D}$ chains. 


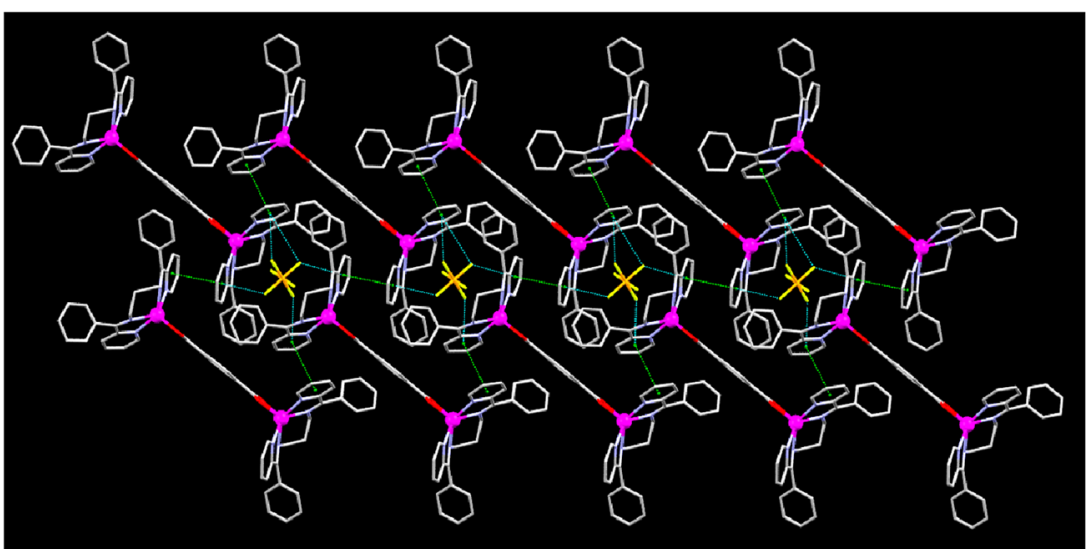

(a)

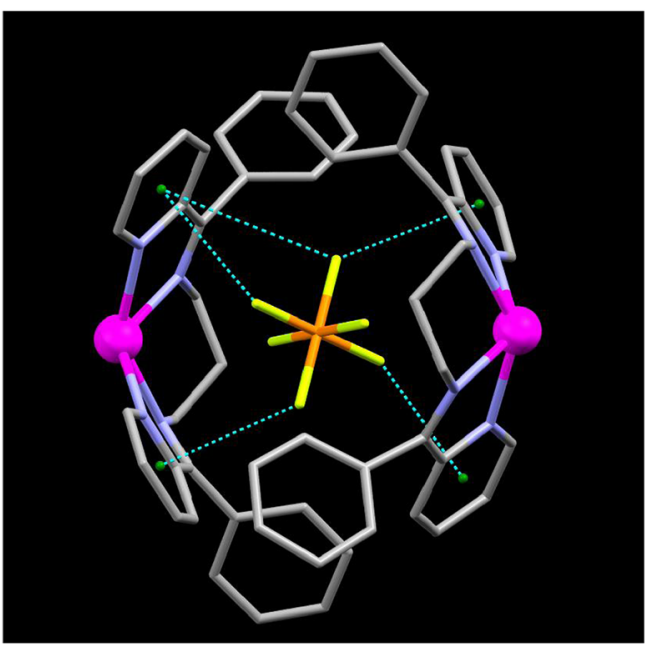

(b)

Figure 4. (a) A view of $2 \mathrm{D}$ sheet structure in $\mathbf{1}$ formed through cooperative $\pi \cdots \pi$ and anion $\cdots \pi$ interactions parallel to ab-plane; (b) a segment of anion $\cdots \pi$ interactions involving pyridine rings and embedded $\mathrm{PF}_{6}^{-}$anion

hydrogen bonds and $\pi \cdots \pi$ interactions in perchlorate salt, but the corresponding hexafluophosphate salt contains $\mathrm{C}-\mathrm{H} \cdots \pi$ and $\pi \cdots \pi$ interactions along with only $\mathrm{C}-\mathrm{H} \cdots \mathrm{F}$ hydrogen bond and with no $\mathrm{O}-\mathrm{H} \cdots \mathrm{O}$ hydrogen bond, though both the salts contain crystallized water molecules. The anion" $\pi$ interaction in $\mathbf{1}$ may presumably arise due to the presence of highly electronegative fluorine in hexafluorophosphate over relatively less electronegative oxygen in perchlorate that influences the packing in the long-range form in crystalline state. This reflects that these two counter anions in the dinuclear manganese(II) complexes have a pivot role in controlling molecular and crystalline architectures of these two compounds containing the same metal ion, blocking ligand and bridging unit.

\subsection{Thermal study}

To examine thermal stability of complex 1, thermogravimetric analysis (TGA) was carried out between $35^{\circ} \mathrm{C}$ to $740^{\circ} \mathrm{C}$ in a static atmosphere of nitrogen. The TG curve shows (figure 6) the compound loses 3.57 units of crystalline water molecules (obs.: 2.172\%, calcd.: $3.994 \%$ ) in the temperature range $40-96^{\circ} \mathrm{C}$ and is stable up to $288^{\circ} \mathrm{C}$. In the second step, it decomposes two Schiff base (L) units and one tp unit (obs.: $69.292 \%$, calcd.: $68.048 \%$ ) in the temperature range $288-724^{\circ} \mathrm{C}$ ultimately giving dirty brown amorphous solid, $\mathrm{Mn}_{3} \mathrm{O}_{4}$ (obs.: 23.238\%, calcd.: 16.000\%). In summary, the thermogravimetric analysis shows that $\mathbf{1}$ has reasonable thermal stability.

\subsection{Magnetic property}

Variable-temperature magnetic susceptibility measurement for 1 has been performed in the 2-300 K temperature range. The $\chi_{M} T$ vs. $T$ plot $\left(\chi_{M}\right.$ is for two $\mathrm{Mn}$ (II) ions) of complex $\mathbf{1}$ is shown in figure 7. The $\chi_{M} T$ value at $300 \mathrm{~K}$ is close to $9.1 \mathrm{~cm}^{3} \mathrm{~mol}^{-1} \mathrm{~K}$ which is as expected for two magnetically quasi-isolated spin 


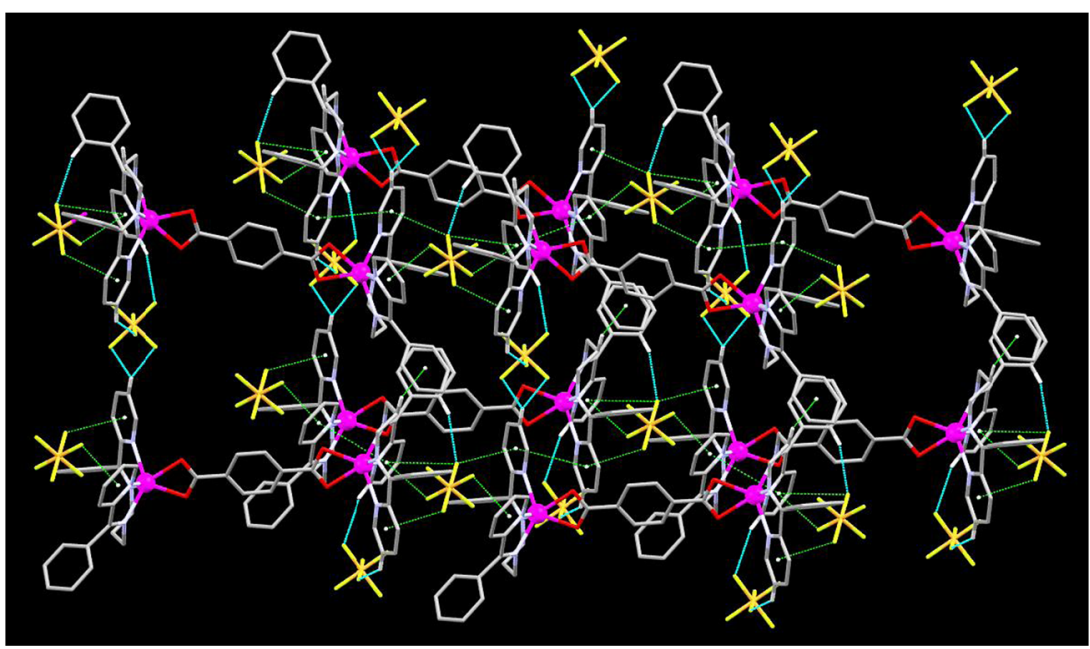

Figure 5. A view of 3D network structure in $\mathbf{1}$ formed through cooperative $\mathrm{C}-\mathrm{H} \cdots \mathrm{F}$ hydrogen bonds, and $\pi \cdots \pi, \mathrm{C}-\mathrm{H}^{\cdots}{ }^{\cdots} \pi$ and anion $\cdots \pi$ interactions.

doublets $(g \sim 2.00)$. This remains practically constant up to $50 \mathrm{~K}$, below which it decreases rapidly to 7.8 $\mathrm{cm}^{3} \mathrm{~mol}^{-1} \mathrm{~K}$ at $2 \mathrm{~K}$. The feature is characteristic of weak anti-ferromagnetic interactions. The reduced molar magnetization at $2 \mathrm{~K}$ (figure 7 inset) clearly corroborates that the anti-ferromagnetic coupling is small. The $M / N \mu_{B}$ value at $5 \mathrm{~T}$ tends to $10.0 \mathrm{~N} \mu_{\mathrm{B}}$ and the curve does follow the Brillouin law. Complex $\mathbf{1}$ is with a dinuclear manganese(II) core. The fit of the susceptibility data has been carried out applying the corresponding formula for a dinuclear $\mathrm{Mn}$ (II) complex, ${ }^{9 a}$ considering the Hamiltonian $\mathrm{H}=-\mathrm{JS}_{1} \mathrm{~S}_{2}$.
The best-fit parameters obtained are: $J=-0.083 \pm$ $0.001 \mathrm{~cm}^{-1}, \mathrm{~g}=2.03 \pm 0.01$ and $\mathrm{R}=1.1 \times 10^{-5}$. The small $J$ value in $\mathbf{1}$ may presumably be due to weak interaction between the two metal(II) centres through intramolecular covalent tp bridging arm and intermolecular non-covalent forces such as hydrogen bonds, and $\pi \cdots \pi, \mathrm{C}-\mathrm{H}^{\cdots} \pi$ and anion... $\pi$ interactions of the same order of magnitude. In summary, the presence of long tp bridge is responsible for weak antiferromagnetism is revealed. The shape of the magnetization curve is in consonance with the Brillouin formula.

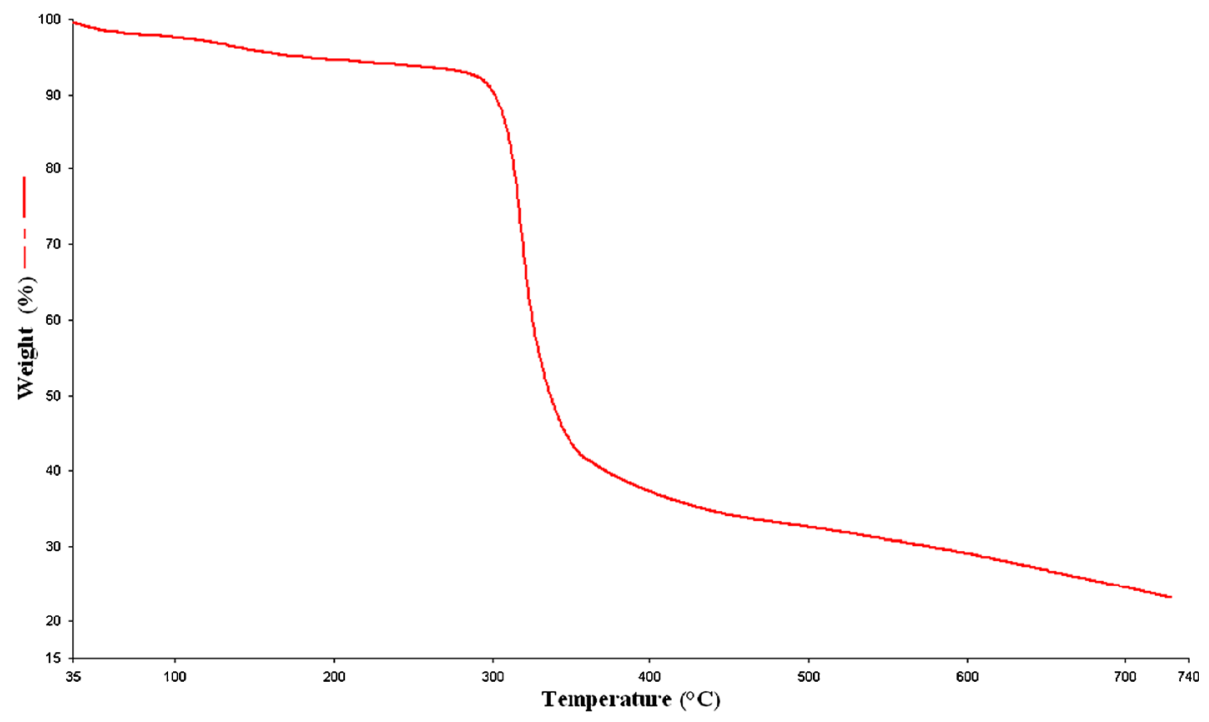

Figure 6. Thermal behaviour of $\mathbf{1}$. 


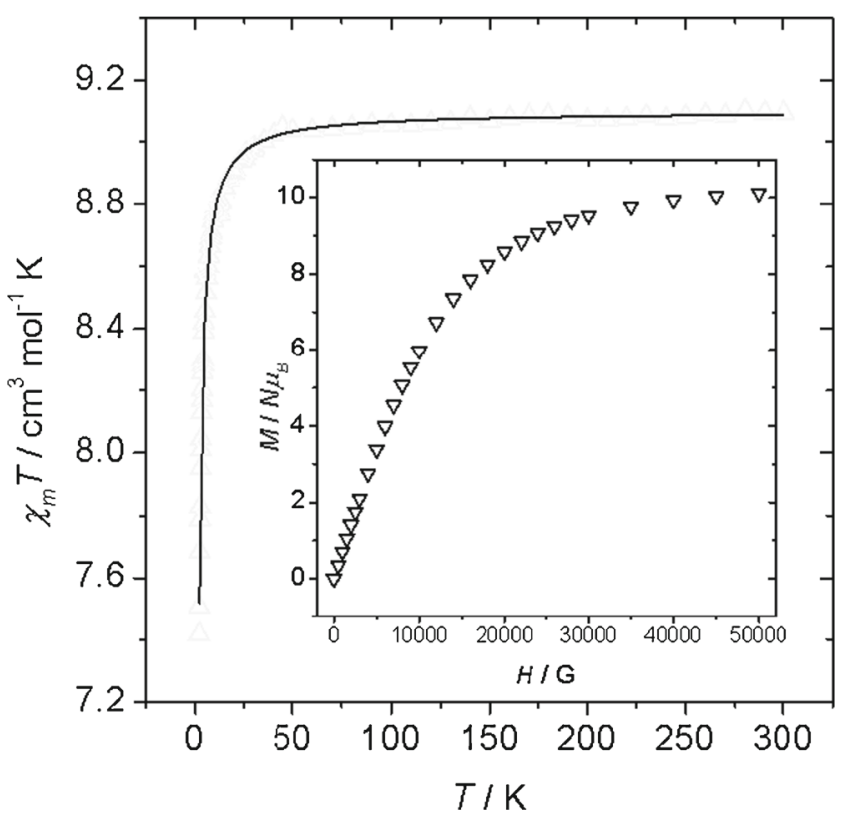

Figure 7. Plots of the $\chi_{M} T$ vs $T$ and $\mathrm{M} / \mathrm{N} \mu_{\mathrm{B}}$ vs $\mathrm{H}$ (inset, $2 \mathrm{~K}$ ) for 1 . Solid line indicates the best fit obtained with the parameters (see text).

\section{Conclusions}

A new dinuclear terephthalate-bridged manganese(II) compound containing a tetradentate Schiff base has been isolated and characterized. The manganese(II) centres adopt a rare trigonal prismatic geometry connected by bis(bidentate) bridging motif of the aromatic dicarboxylate. Several weak non-covalent interactions such as hydrogen bonds and $\pi \cdots \pi, \mathrm{C}-\mathrm{H} \cdots \pi$ and anion $\cdots \pi$ interactions act in cooperative manner to promote dimensionality of the OD dinuclear compound. The presence of unique anion $\cdots \pi$ interaction in $\mathbf{1}$ which is absent in the analogous percholorate compound $\left[\mathrm{Mn}_{2}(\mathrm{~L})_{2}(\mu\right.$-tp) $]\left(\mathrm{ClO}_{4}\right)_{2} \cdot \mathrm{H}_{2} \mathrm{O}$ is noteworthy. The presence of octahedral hepta-atomic hexaflurophosphate counter anion over tetrahedral penta-atomic perchlorate may have a major role in such a unique interaction while embedding in the network. Variable-temperature magnetic susceptibility measurements show weak antiferromagnetic coupling between the metal centres mediated through long tp bridging. We are now extending this work using other $3 \mathrm{~d} / 4 \mathrm{~d}$ metal ions in combination with different Schiff bases/polyamines and tailored polycarboxylates.

\section{Supplementary Information}

Crystallographic data for the structural analysis has been deposited with the Cambridge Crystallographic data centre No. 963133 (1). Copy of this information can be obtained, free of charge from The Director, CCDC, 12 Union Road, Cambridge, CB2 1EZ, UK (fax: +44 1223 336033; e-mail: deposit@ccdc.cam.ac.uk or http://www.ccdc.cam.ac. uk).

\section{Acknowledgements}

Financial support from the CSIR, New Delhi, India is gratefully acknowledged. The authors S. Choubey, S. Chattopadhayay, K. Bhar and S. Khan are grateful to CSIR and S. Roy to UGC, New Delhi, India for fellowships. Prof. J. Ribas thanks Spanish Government (GrantCTQ2012/30662) for financial support. The authors are also thankful to Prof. L. J. Barbour, Department of Chemistry, University of Stellenbosch, Stellenbosch 7600, South Africa for X-ray crystallographic study of the compound.

\section{References}

1. (a) Lehn J M 1995 In Supramolecular Chemistry: Concepts and Perspectives (Weinheim: VCH); (b) Steed J W and Atwood J L 2009 In Supramolecular Chemistry (New York: Wiley)

2. (a) Braga D, Grepioni F and Orpen A G 1999 In Crystal Engineering: From Molecules and Crystals to Materials (Dordrecht: Kluwer); (b) Tothadi S, Mukherjee A and Desiraju G R 2011 Chem. Commun. 47 12080; (c) Desiraju G R 2013 J. Am. Chem. Soc. 1359952

3. (a) Jeffrey G A 1997 In An Introduction to Hydrogen Bonding (Oxford: Oxford University Press); (b) Desiraju G R 2011 Angew. Chem. Int. Ed. 50 59; (c) Reedijk J 2013 Chem. Soc. Rev. 42176

4. (a) Tiekink E R T and Schpector J Z (eds.) 2012 In The Importance of Pi-Interactions in Crystal Engineering: Frontiers in Crystal Engineering (Chichester: John Wiley); (b) Kawase T and Kurata H 2006 Chem. Rev. 1065250

5. (a) Nishio M, Hirota M and Umezawa Y 1998 In The $\mathrm{CH} / \pi$ Interaction (New York: Wiley-VCH); (b) $\mathrm{Hu} \mathrm{M}$, Wang X, Jiang Y and Li S 2008 Inorg. Chem. Commun. 1185

6. (a) Gamez P, Mooibroek T J, Teat S J and Reedijk J 2007 Acc. Chem. Res. 40 435; (b) Mooibroek T J, Black C A, Gamez P and Reedijk J 2008 Cryst. Growth Des. 8 1082; (c) Mooibroek T J, Gamez P, Reedijk J 2008 CrystEngComm. 10 1501; (d) Schottel B L, Chifotides H T and Dunbar K R 2008 Chem. Soc. Rev. 37 68; (e) Frontera A, Gamez P, Mascal M, Mooibroek T J and Reedijk J 2011 Angew. Chem. Int. Ed. 50 9564; (f) Zhao Y, Domoto Y, Orentas E, Beuchat C, Emery D, Marada J, Sakai N and Matile S 2013 Angew. Chem. 12510124

7. (a) Estarellas C, Frontera A, Quiňonero D and Deyà PM 2011 Angew. Chem. Int. Ed. 50 415; (b) Salonen L M, Ellermann M and Diederich F 2011 Angew. Chem. Int. Ed. 50 4808; (c) Brooker S, White N G, Bauzaì A, Deyaì P M and Frontera A 2012 Inorg. Chem. 51 10334; (d) Wang D X, Wang M X 2013 J. Am. Chem. Soc. 135 892; 
(e) Chifotides H T and Dunbar K R 2013 Acc. Chem. Res. 46894

8. (a) Seth S K, Saha I, Estarellas C, Frontera A, Kar T and Mukhopadhyay S 2011 Cryst. Growth Des. 11 3250; (b) Manna P, Seth S K, Das A, Hemming J, Prendergast R, Helliwell M, Choudhury S R, Frontera A and Mukhopadhyay S 2012 Inorg. Chem. 51 3557; (c) Seth S K, Manna P, Singh N J, Mitra M, Jana A D, Das A, Choudhury S R, Kar T, Mukhopadhyay S and Kim K S 2013 CrystEngComm. 15 1285; (d) Mitra M, Manna P, Seth S K, Das A, Meredith J, Helliwell M, Bauzaì A, Choudhury S R, Frontera A and Mukhopadhyay S 2013 CrystEngComm. 15686 and references therein

9. (a) Kahn O 1993 In Molecular Magnetism (New York: VCH); (b) Miller J S and Gatteschi D 2011 Chem. Soc. Rev. 403053

10. (a) Rowsell J L C and Yaghi O M 2005 Angew. Chem. Int. Ed. 44 4670; (b) Czaja A U, Trukhanb N and Müller U 2009 Chem. Soc. Rev. 38 1284; (c) Murray L J, Dinca M and Long J R 2009 Chem. Soc. Rev. 38 1294; (d) Lee J Y, Farha O K, Roberts J, Scheidt K A, Nguyen S T and Hupp J T 2009 Chem. Soc. Rev. 381450

11. (a) Pashow K M L T, Rocca J D, Xie Z, Tran S and Lin W 2009 J. Am. Chem. Soc. 131 14261; (b) Sumida K, Rogow D L, Mason J A, McDonald T M, Bloch E D, Herm Z R, Bae T H and Long J R 2012 Chem. Rev. 112 724; (c) Wang C, Zhang T and Lin W 2012 Chem. Rev. 1121084

12. (a) Rao C N R, Natarajan S and Vaidhyanathan R 2004 Angew. Chem. Int. Ed. 43 1466; (b) Ye B H, Tong M L and Chen X M 2005 Coord. Chem. Rev. 249 545; (c) LaDuca R L 2009 Coord. Chem. Rev. 253 1759; (d) Lin Z, Tong M L 2011 Coord. Chem. Rev. 255421

13. (a) Ma C B, Hu M Q, Chen $\mathrm{H}$, Wang M, Zhang C X, Chen C N and Liu Q T 2010 CrystEngComm. 12 1467; (b) Yuan W, Garay A L, Pichon A, Clowes R, Wood C D, Cooper A I and James S L 2010 CrystEngComm. 12 4063

14. (a) Sain S, Maji T K, Mostafa G, Lu T H and Chaudhury N R 2003 Inorg. Chim. Acta 351 12; (b) Maji T K, Sain S, Mostafa G, Lu T H, Ribas J, Monfort M and Chaudhury N R 2003 Inorg. Chem. 42, 709; (c) Ghosal D, Maji T K, Mostafa G, Lu T H and Chaudhury N R 2003 Cryst. Growth Des. 39

15. (a) Cano J, Munno G De, Sanz J L, Ruiz R, Faus J, Lloret F, Julve M and Caneschi A 1997 J. Chem. Soc. Dalton. Trans. 1915; (b) Palanisami N and Murugavel R 2011 Inorg. Chim. Acta 365 430; (c) Deniz M, Rodŕíguez I H, Pasań J, Fabelo O, Delgado L C, Yuste C, Julve M, Lloret F and Perez C R 2012 Cryst. Growth Des. 124505

16. (a) Ma C, Chen C, Liu Q, Liao D, Li L and Sun L 2003 New J. Chem. 27 890; (b) Manna S C, Konar S, Zangrando E, Okamoto K I, Ribas J and Chaudhuri N R 2005 Eur. J. Inorg. Chem. 4646; (c) Liu J Q, Zhang Y N, Wang Y Y, Jin J C, Lermontova E Kh and Shia Q Z 2009 Dalton. Trans. 5365

17. (a) Jiang Z Q, Zhao Z, Jiang G Y, Hou D C, Kang Y 2011 Inorg. Chem. Commun. 14 1975; (b) Kumagai H, Sakamoto Y, Kawata S, Matsunaga S and Inagaki S 2012 Bull. Chem. Soc. Jpn. 85 1102; (c) Gómez V, Corbella M, Mautner F A, Roubeau O, Teat S J, Bardia M F and Calvet T 2012 Polyhedron $\mathbf{4 5} 185$
18. (a) Hong C S and Do Y 1997 Inorg. Chem. 36 5684; (b) Chen C, Huang D, Zhang X, Chen F, Zhu H and Liu Q 2003 Inorg. Chem. 42 3540; (c) Hong C S, Yoon J H and You Y S 2005 Inorg. Chim. Acta 3583341

19. (a) Chakrabarty R, Mukherjee P S and Stang P J 2011 Chem. Rev. 111 6810; (b) Ward M D and Raithby P R 2013 Chem. Soc. Rev. 421619

20. (a) Stock N and Biswas S 2012 Chem. Rev. 112 933; (b) Zhao D, Timmons D J, Yuan D and Zhou H C 2011 Acc. Chem. Res. 44 123; (c) Qiu S and Zhu G 2009 Coord. Chem. Rev. 2532891

21. (a) Li H, Eddaoudi M, O'Keeffe M and Yaghi O M 1999 Nature 402 276; (b) Rosi N L, Eckert J, Eddaoudi M, Vodak D T, Kim J, O'Keeffe M and Yaghi O M 2003 Science 300 1127; (c) Wang G H, Li Z G, Jia H Q, Hu N H and Xu J W 2008 Cryst. Growth Des. 81932

22. (a) Vigato P A and Tamburini S 2004 Coord. Chem. Rev. 248 1717; (b) Vigato P A, Peruzzo V and Tamburini S 2012 Coord. Chem. Rev. 256953

23. (a) Choubey S, Roy S, Bhar K, Ghosh R, Mitra P, Lin C H, Ribas J and Ghosh B K 2013 Polyhedron 55 1; (b) Choubey S, Roy S, Khan S, Ghosh R, Bhar K and Ghosh B K 2013 J. Indian Chem. Soc. 90 807; (c) Kundu S, Roy S, Choubey S, Bhar K, Ghosh P K, Mitra P and Ghosh B K 2013 J. Mol. Struct. 105141

24. (a) Roy S, Sarkar B N, Bhar K, Satapathi S, Mitra P and Ghosh B K 2013 J. Mol. Struct. 1037 160; (b) Roy S, Choubey S, Bhar K, Khan S, Mitra P and Ghosh B K 2013 J. Mol. Struct. 1051 328; (c) Roy S, Choubey S, Khan S, Bhar K, Mitra P and Ghosh B K 2013 J. Chem. Sci. 125715

25. Verdaguer M, Gouteron J, Jeannin S, Jeannin Y and Kahn O 1984 Inorg. Chem. 234291

26. Sheldrick G M 1996 SAINT, V4: Software reference manual, Siemens analytical X-ray systems Madison, WI, USA

27. Sheldrick G M 1996 SADABS: Program for empirical absorption correction of area detector data, University of GÖttingen, Germany

28. Sheldrick G M 2008 Acta Crystallogr. Sect., A 64112

29. Spek A L 2009 Acta Crystallogr. Sect., D 65148

30. Pennington WT 1999 J. Appl. Crystallogr. 321028

31. Barbour L J 2001 J. Supramol. Chem. 1189

32. Macrae C F, Edgington P R, McCabe P, Pidcock E, Shields G P, Taylor R, Towler M and Streek J van de 2006 J. Appl. Crystallogr. 39453

33. Geary W J 1971 Coord. Chem. Rev. 781

34. (a) Massoud S S, Mautner F A, Vicente R and Sweeney H N 2006 Inorg. Chim. Acta. 359 1489; (b) Nakamoto K 2009 In Infrared and Raman Spectra of Inorganic and Coordination Compounds Part B $6^{\text {th }}$ ed. (New Jersey: John Wiley)

35. (a) Lever A B P 1984 In Inorganic Electronic Spectroscopy $2^{\text {nd }}$ ed. (New York: Elsevier); (b) Sole J G, Bausa L E and Jaque D 2005 In An Introduction to the Optical Spectroscopy of Inorganic Solids (New York: John Wiley)

36. (a) Cremades E, Echeverr J and Alvarez S 2010 Chem. Eur. J. 16 10380; (b) Mukherjee S, Patil Y P and Mukherjee P S 2012 Inorg. Chem. 51 4888; (c) Choubey S, Roy S, Bhar K, Mitra P, Ribas J and Ghosh B K 2014 Polyhedron 74134

37. Etter M C 1991 J. Phys. Chem. 954601 